\title{
PERFORMING MUSICALIZATION OF POETRY AND UPLOADING THE VIDEO ON YOUTUBE FOR POETRY CLASS PROJECT
}

\author{
Febriyanti Dwiratna Lestari \\ UIN Sunan Kalijaga Yogyakarta
}

\begin{abstract}
Musicalization of poetry is an intriguing class project for English Literature students. It enables them to dig into their creativity and talent in writing and performing poetry and at the same time speeding up their comprehension of English poetry, particularly from the aspect of musical device of a poem. Though not treated as the main activity of the course, such task is valuable, acommodating those interested more in producing literary work than merely criticizing it. Also, to make this project more fun, the students can be challenged to videotape their performance and share it on YouTube. The students are thus encouraged to pack it in a good video presentation because their videos, once uploaded and set public, become available for any viewers. This project may work best if assigned for a group work because the students could delegate jobs such as who is to write and recite the poem, to design the concept of their musicalization of poetry, to tape and edit the video, and finally to upload the video on YouTube and promote it on social media like Facebook and Twitter. Indeed, musicalization of poetry project could be taken as an extra assignment in poetry class by which the students practice employing the poetic devices at first hand. This paper will explain the why, what and how this class project should be conducted.
\end{abstract}

Key words: musicalization of poetry, YouTube video upload, poetry class project

\section{INTRODUCTION}

In most universities in Indonesia, if not all, the bottom line of the curriculum of Literature department weighs more on courses which are designated to criticize existing works both classic and popular than producing poems, plays 
and novels. It is to support the vision of the department whose projected outputs are experts in literary studies, linguistics, and translation but not poets, playwrights, nor novelists. Perhaps, it is because the latter professions are considered less promising than the former. If there is an alumnae who ends up being a novelist, for example, often it is largely because of his or her own talent as he or she cannot rely on the formal courses offered to help develop their skill in literary writing practically. Moreover, the teaching-learning process in the classroom only makes a very little room, if there is, to appreciate the student's literary work. And it is especially true of English Literature Department. In Sunan Kalijaga State Islamic University, for example, only creative writing course accomodates itbut this course alone is offered as one of the elective courses, not a compulsory subjectdespite the fact that the students can practice their English through writing poems or short stories and produce works which are based upon English literary works such as in the form of parody, satire, or series.

On the one hand, the existing model of curriculum is good in a way that it provides the students of English Literature Department with adequate knowledge of both Western Literature and culture, particularly British, American, and Australian and the literary devices as the tools by which to analyze the works. To some extent, they could learn something of the style, structure, themes, and messages of the masterpieces of the famous poets, playwrights, novelists from these countries and be inspired for their own writing. Unfortunately, however, in practice the students are assigned to use literary devices and apply literary theories in order to scrutinize the existing works only regardless of the greater chance for students to familiarize themselves with the given works and fully comprehend them by direct experience. Their ultimate project is to write a graduating paper analyzing a literary work if their concentration is literatureor language phenomena if linguisticsand they are not permitted to replace it with submitting own poem, play, or prose.

On the other hand, the curriculum of English Literature Department in general is unable to satisfy the interest of some students for producing literary works. Students who are talented as an artist or an author are not well facilitated. Instead, they would rather look for any opportunity to develop their skills without relying on formal courses. Some get involved in extra-curricular activities on and off campus such as by joining local community that is concerned with arts, literature, and culture. Some others sign up on a website which enables the 
members to publish poems or other literary works and offer them a chance to join online competition.

Indeed, this is a dilemma that has to be dealt with. It is partly the job of English Literature teacher to find the ways to meet the target set in the curriculum while still giving room for student's creativity in writing literary text. It is especially true of poetry class since poetry often sounds frightening or boring for most students. One of the solutions is assigning the students musicalization of poetry project. Such a performance enables them to dig into their creativity and talent in writing and performing poetry and at the same time speed up their comprehension of English poetry, particularly from the aspect of musical device of a poem. It is necessary to seek whether this performance benefits them if assigned in a compulsory course.In addition, it will be more challenging if they are to videotape the performance and upload it on YouTube.

This paper will describe the steps to carry to conduct the project beginning with writing the poem and musicalizing it, plus videotaping the performance and uploading the video on YouTube. And before going further to the YouTube project, however, it will first briefly explain the reasons why choosing musicalization of poetry as the project and YouTube as the media by which to upload the video?

\section{WHY MUSICALIZATION OF POETRY?}

There is no clear definition of musicalization of poetry. To quote from Oxford dictionary, to "musicalize" (verb) means "to set (a novel, play or poem) to music. When applied to play, Bouko (2010) defines musicality, or musicalité in French, as "a musical construction of a performance, therefore a piece of theatre which is constructed as music." To put it simply, in this case, it is a poem which is constructed as music. But what kind of music? How to combine the poem and the music?

Historically speaking, musicalization of poetry is not a new invention. It has been there as early as a poem was created. It started out as an oral performance. In Africa, it used to be performed as a ritual. In America, the Native Americans delivered it in the form of storytelling. In the context of Western Literature, lyrical poetry itself is derived from the word "lyric" which was used to refer a poem reading accompanied by lyre, a musical instrument. Today, as Michael Dana Gioia (2003) says, "the new oral poetry" like "rap" is emerging. Further, "much of the 
new popular poetry is never written down; it exists only as sounds shaped in the air. When there is a text, it was often created post factum by transcribing a recorded performance from audio- or videotape." From these, the students can learn how oral performance has been conducted from time to time in different milieu. Then they can choose their preferred model for their musicalization of poetry.

Moreover, in his article "Turning Poetry Into Music", John Lundberg (2008) wrote that "there is a long tradition of adapting poetry into song. Formal verse, with its built-in metrical regularity and attention to musical qualities, sometimes translates pretty easily." According to Indonesia's Department of National Education (2012), musicalization of poetry, like poem reading or dramatized poem, is one of the ways or techniques to articulate and deliver poem to the audience. However, more than just reciting a poem, it is very much concerned with not only the precise pronunciation and expression which reinforce the content and meaning of the poem but also the tone, meter, and rhythm as its defining elements since it will be aided by musical instrument.

Most importantly, however, it must be noted that all musicalization of poetry is carried out to serve the purpose, to highlight the messages conveyed in the poem. Although the way the poetry is performed has undergone some changes and adaptations to where and when it is produced, it is agreed that the technique of saying or delivering the poem aloud is very significant to the meanings and functions of a poem. As Seamus Heaney describes,

Every time you listen to another person reading out a poem, in school or on a stage or in a studio, every time you read a poem aloud to yourself or in the presence of others, you are also reading it into yourself and them. Voice helps to carry words farther and deeper than eye. These recordings maintain a tradition of oral performance that is as old as the art of poetry itself."

All in all, musicalization of poetry is a process of creating a poetically musical performance in which the starting point is the poem itself, and the main goal of that activity is to make the messages and meanings of the poem clearer and stronger.

\section{WHY YOUTUBE AND ONLINE SOCIAL MEDIA?}

In this digitization era, internet is an inevitable part of our daily businesses. Websites offer a wide range of information useful for people of all ages, accessible at anytime and place. In Indonesia, internet users in urban area has risen 
significantly. Based on a survey on internet users conducted by Coolfounders.com in 2010, it was found that "the number of Internet users in Indonesia is growing really fast (the highest growth among Asia countries after China), especially the number of users who use their mobile phone to access the Internet." It was also projected that in 2015 about more than half of the Indonesian population or 150 million people would have access to the Internet mostly through their mobile phone. Another interesting finding of the survey was that Indonesians "are very enthusiastic to online social networking. 28 million Indonesians have account(s) with Facebook, making them the $3^{\text {rd }}$ largest Facebook users in the world. As of June 2010 , Indonesians also produced the $3^{\text {rd }}$ highest number of tweets in the world."

In education field alone, search engine like Google enters the classroom. There is no reason to not look up to Wikipedia or Online Oxford Dictionary when some unknown word or mythological figure is brought up during the class. Moreover, it is almost impossible now to find a student and teacher who has not had an email account, and what is more, account on social media like Facebook, Twitter, Blogger, YouTube, or else. Outside the classroom the interaction between teachers and students continue. While email is still commonly used as a medium for students to submit their assignment or papers, Facebook is king in Indonesia. More and more Facebook groups are created everyday as a forum for communication, information sharing, and consultation among teachers-teachers, students-students, and teachers-students.

If Facebook is a king, YouTube is a giant. According to Hengky Prihatna, a country Google consultant, there are approximately 30 millions of YouTube users in Indonesia. It becomes the second largest search engine, focused on video search. Looking at this trend and opportunity, teachers had better not delay putting YouTube into use in their teaching and learning activity. According to Katie Lepi, teachers can use it to (1) search for on-topic videos that can be used in the classroom to bring lessons to life, making them more memorable; (2) record the lessons and post them so students can review them whenever they want; (3) take videos to the next level by adding quizzes, annotations and more; (4) curate organized playlists so the students can easily find and watch all related and approved videos on a topic; and (5) teach students how to produce and edit video by having them film and upload videos to a class YouTube channel. Among the five, the last strategy is the closest to student-centered approach. It offers a greater chance for students to be familiar in operating the features on YouTube and feel its advantage for themselves. 
Apparently, the use of YouTube during a teaching-learning process is applicable to almost every course. Using strategy number five, the video-upload by students can be taken as a class project. In this case, the video to upload is the student's own musicalization of poetry performance. This kind of project is chosen as it not only helps the students to comprehend the poetic devices by experiencing poetry at first hand but also allows them to explore their creativity in arts as well as build their confidence.

\section{WRITING THE POEM AND MUSICALIZING IT}

Though not all students of English literature have talent and skill to write an excellent poem, they might be challenged to do so. Therefore, providing the students with a chance to produce own poems would be valuable experience for them. Pior to this, of course, the teachers must introduce them to some common types of English poetry; for examples, sonnets, blank verse, free verse, lyrical poetry. The students should first identify the elements of each of the poemsparticularly the musical devicesand see how the rhyme and rhythm work in it, constructing or highlighting the meaning of the poem. From the given sample poems, they would attain applicable knowledges and reference by which to develop their own poem later.

Indeed, the students would find difficulties during the poetry writing process. For some, they might be forced to work really hard to produce one as there are a lot of poetic devices that they have to consider to make their poem right. To overcome this problem, teachers may assign this poetry writing task in groupwhile individual work is still possible if most of the students show great passion to do this. And throughout the process, poetry teacher should always be there assisting the students, to make sure they are working on the right track. Here the student's creativity is put to the test.

In practice in the classroom, anything is possible to happen. It cannot be denied that sometimes poetry teachers should anticipate a student whose motivation and interest to poetry is very low. At worst, the students may be permitted to pick any of the British or American poems as the source material for their musicalization of poetry, but they have to make sure that they mention credit to it on their video later. Such an option is not suggested, however, as it reduces their efforts to experience producing poetry at first hand. 
When the text for their performance is already at hand, the next step they have to do is design the concept for their musicalization of poetry. As previously mentioned, the models of oral performance vary. They may simply recite the poem with pertinent expressions and stress while being accompanied by sound of musical instrument like guitar, piano, violin, etc which can enhance the spirit of the poem. They may act it out theatrically like a fragment of a play. In this way, they advance to choosing the right dress or costumes to wear, choosing and designing the setting which can reflect the nuance that the poem desires, and arranging the piece of plot which is in accordance with the story in the poem. Also, they may compose a song based on the poem they have written. In this way, they can start from making the basic melody, arranging the music notes, up to editing.

At this stage, the student practices reading the poem aloud. They have to be very careful with the meter of each line, the stresses, pause so as to accentuate the theatrical touch which is necessary for their performance. Also, they should consider the rhyme arrangement, the reffrain to build up the music.

\section{VIDEOTAPING THE PERFORMANCE AND UPLOADING THE VIDEO ONYOUTUBE}

After the students are finished with their poetry writing and its musicalization, they can proceed to videotaping process. The challenge at this level is related with their competence to operate the devices provided by the technology. The main hardware needed here is video camera, either one that is integrated within their mobile phone or a handycam. The softwares that can be run to edit the video are like Microsoft movie maker, Vegas, etc. Without these hardware and software, this process would not be possible.

As already stated, musicalization of poetry as part of English Literature class project, especially under the subject of poetry, would be more suitable if implemented as a group workdespite the fact that it is potentially done individually, too. Group work not only eases the student's job but also enables a better performance. To quote a proverb, "two heads are better than one." Besides, more roles can be played in group. The student can read some lines after another which helps enhance the artistic aspect. Moreover, more personnels make the members of a group effortlessly design the setting for their performance because they should make sure the details of the setting are relevant with the meaning of the poem. 
The duration for performing the musicalization of poetry is around 3 to 10 minutes longwhich is considerably appropriate for one-poem performance. A shorter duration may be insufficient to convey the message of a poem. However, lengthy video which is above 10 minutes may be boring. It is especially true on YouTube, viewers are likely to lose interest if the video is too long. Within this duration range, the video must have included the identity such as the title of the poem and name of the performers. These elements are inserted during the video editing process.

When the video is ready, the students can start uploading it on YouTube. For this, they are required to have an email address which links to YouTube or at least an account on this website. YouTube is chosen as a site to upload the video because it is home to everyone's videos which means the students have more chance for their videos to be viewed by people. According to a fact sheet on YouTube demographics, it is found that $51 \%$ of YouTube users visit weekly or more often. It means that their video can also be taken as reference for others. Besides, YouTube enables easy posting of video by a usersimply by browsing the file on the computer memory and clicking upload button on YouTube accountand easy viewing by visitors, just to type the filename "musicalization of poetry" in the search bar and click search. Moreover, a survey of nearly 2,000 faculties in the U.S. this year, conducted by education publisher Pearson found that many consider YouTube a "very valuable" classroom aid.

YouTube contains millions of videos. A bunch of videos from around the world are uploaded everyday. People are likely to browse videos which are controversial, popular, and commercial, and thus video on musicalization of poetry produced by an amateur like this would be very unlikely to be people's priority to search. Therefore, the students must promote it to others. It can be informed on campus among their friends, from mouth-to-mouth, face to face. More effectively, they can use popular social media like Facebook and Twitter by providing the site address. Their friends on Facebook or followers on Twitter can be directed to watching the video on YouTube by simply clicking the link provided.

\section{CONCLUSION AND SUGGESTION}

Performing musicalization of poetry is a fascinating project to be assigned for English Literature students, particularly poetry class. This way they not only learn to read and analyze Shakespeare's sonnets or Housman's lyrics using the 
poetic devices but also experience at first hand how to write, to practice applying the musical devices and perform their own poems. In addition, since they are required to videotape their musicalization of poetry performance and upload it on YouTube, they are able to watch and share their videos at anytime and place. Of course, the model of the project presented here is far from perfect and needs to be improved and polished in a lot of aspects and methods. Therefore, further studies related to such this kind of project is welcome.

\section{REFERENCES}

Sweney, M. "The Rise and Rise of YouTube: YouTube overtakes MySpace". Media

Guardian.com. July 31, 2006. September 1, 2012. Web.

Odden, L. "Social Media Advertising on YouTube, Facebook, Twitter \& All Social Media In User Satisfaction.” 2011. September 15, 2012. Web.

Lepi, K. "25 Ways Teachers Can Integrate Social Media Into Education". Edudemic. com, July 28, 2012. September 1, 2012. Web.

Marklein, M. B. “Teachers Embrace Social Media in Class”. USA Today. April 3, 2012. September 1, 2012. Web.

Rustandi, N. "Indonesia Now! A Broader Look at Indonesian Startups and Internet Business Prospects." Coolfounders.com. 2010. September 1, 2012. Web.

Kurniawan, S. "Digital Marketing, Sebuah Kemutlakan.” The Marketeers Web. February 17, 2012. September 15, 2012. Web.

. "Brosur Festival Musikalisasi Puisi Bagi Siswa SLTA Sejabodetabek Bulan Bahasa dan Sastra 2012." Badan Pengembangan dan Pembinaan Bahasa Kementerian Pendidikan dan Kebudayaan. October 2012. October 1, 2012. Web.

. "Learning Poetry and Performance." Poetry and Performance. British Library. 2012. September 1, 2012. Web.

Lundberg, J. "Turning Poetry Into Music". Huffingtonpost.com. September 14, 2008. September 1,2012. Web.

Gioia, D. "Disappearing Ink: Poetry at the End of Print Culture." The Hudson Review. Vol. LVI, Number 1 (Spring 2003). September 1, 2012. Web. 